\title{
EXPERIMENTAL FLOW STUDY OF THE GAMM TURBINE MODEL
}

\author{
François Avellan, Philippe Dupont, Mohamed Farhat, Bernard Gindroz, Pierre Henry, \\ Mahmood Hussain, Etienne Parkinson, Olivier Santal \\ EPFL, Institut de Machines Hydrauliques et de Mécanique des Fluides \\ 33, avenue de Cour, CH 1007 Lausanne, Switzerland
}

\section{SUMMARY}

An experimental study of flow in a Francis hydraulic turbine, especially designed for the GAMM Workshop, has been carried out. In order to provide a data base for the validation and comparison of computational fluid dynamics codes, a Francis turbine model and adequate instrumentation have been specially developed. Measurements of both global and local quantities have been performed for the best operating point of the turbine. A fivehole probe mounted on a remote traversing system provides static pressure and velocity components along three measurement axes in the machine. Pressure transducers mounted on the pressure and suction sides of the rotating blades of the runner provide the pressure distribution over the blades in 28 points (17 on the suction side and 11 on the pressure side) arranged along three theoretical streamlines.

\section{INTRODUCTION}

For the GAMM workshop on the computation of incompressible internal flows, IMHEF has provided a full geometry of a Francis turbine. A model Francis turbine was built according to the specified geometry and tested in the IMHEF test facilities, in order to compare the results produced by various CFD codes used by the participants with the measured data. These tests provided as well a proper specification of the test case flow conditions. In this experimental model setup, special features were included, such as, an adjustable stayring, probe passages and pressure taps on the stationary parts. The runner blades were equipped with pressure transducers for measuring the pressure distribution on the blade surfaces.

The aim of this paper is to provide a brief description of the experimental setup used for studying the flow pattern in a model Francis turbine. Special attention was paid to the design of the flow survey instrumentation consisting of a five-hole probe mounted on a remote traversing system, and the pressure measurement system used in the rotating runner. Detailed results of the flow survey in three different locations of the model are given for the best operating point during the tests carried out using the IMHEF Universal Hydraulic Machine Test Facility [1].

\section{THE MODEL OF FRANCIS TURBINE}

\section{GENERAL DESIGN}

The test model corresponds to a Francis turbine of medium-high specific speed, $v=0.5, \quad\left(n_{q}=76\right)$. This model was specially designed by IMHEF only for research 
purposes in order to perform experimental flow studies. A Piguet-type spiral case was designed to give a constant meridional velocity distribution. A fillet was added on both sides of the stayring inlet in order to assure well-defined inflow conditions.

The stayring consists of 24 stay-vanes and the distributor of 24 guide-vanes. The relative angular position of these two cascades is adjustable, but, for the present study, the angular positions $\theta_{\mathrm{d}}$ and $\theta_{\mathrm{ad}}$ remained unchanged and were set to $26.5^{\circ}$ and $6.5^{\circ}$ respectively, see Figure 1. A mechanical encoder provides a readout of the guide vane opening angle $\alpha$. Since the closed position of the guide vanes corresponds to $\alpha=0^{\circ}$ and an angle $\gamma_{\mathrm{d} 0}=5.37^{\circ}$, as indicated in Figure 1, the opening angle $\alpha$ is related to the guide vane angle as follows :

$$
\gamma_{\mathrm{d}}=\alpha+\gamma_{\mathrm{d} 0}
$$

The runner has 13 blades, each individually casted in epoxy resin reinforced with carbon fiber. The blades are fixed in between an aluminium hub and shroud. The runner outlet diameter is $0.4 \mathrm{~m}$. Top view of the horizontal cross-sections of both the pressure and the suction sides of the blade are given in Figure 2.

The draft tube has a simple shape. It was designed to provide for numerical simulation work a simplified geometry without any inner pillar. It consists of an inlet cone, a constant section bend and an outlet cone. The geometry of the draft tube is shown in Figure 3.

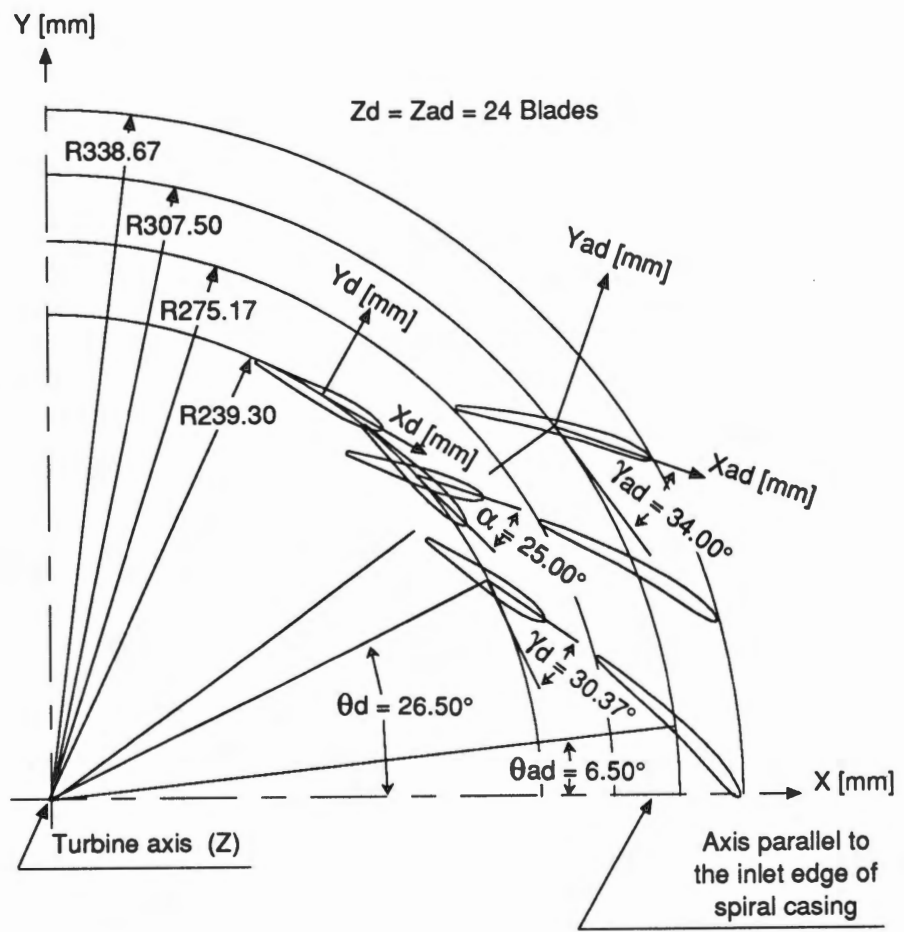

Fig. 1 Stayring and guide-vanes, top view 


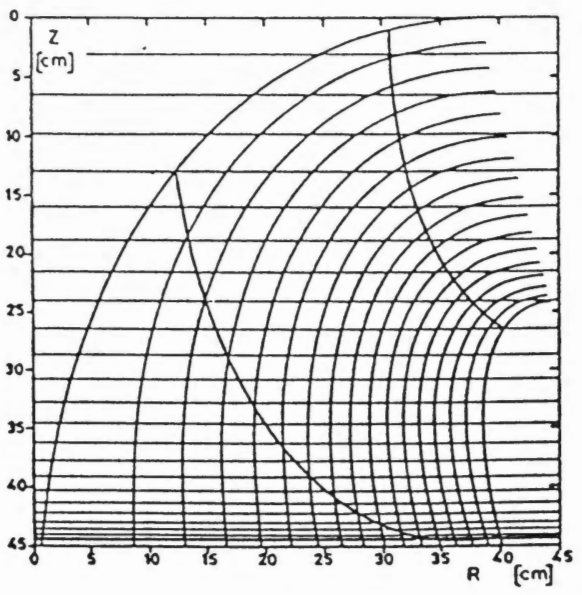

Horizontal cross-section levels and theoretical streamlines in the meridional view

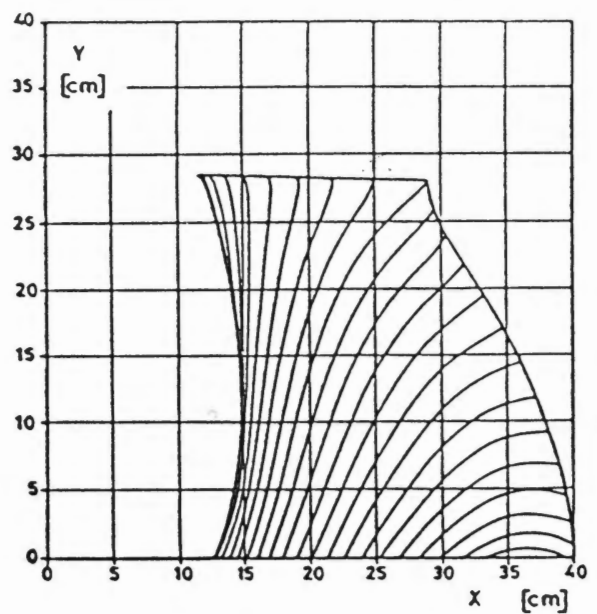

Top view pressure side

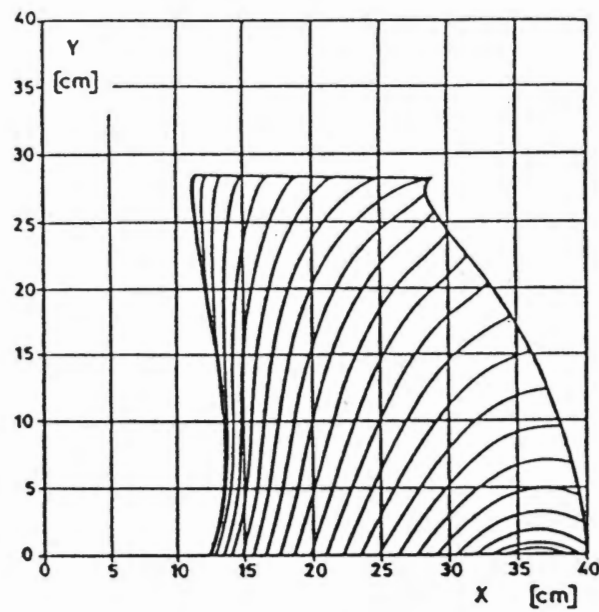

Top view suction side

Fig. 2 Runner blade horizontal cross-sections

\section{FLOW SURVEY SYSTEM}

More than 60 probe passages in the model were planned in order to perform a complete flow survey. They are placed at the stayring inlet, at the runner inlet and outlet, and in a cross-section of the plexi-glass cone. The location of these passages and their corresponding measurement axis are defined in Figure 4. A special mechanical arrangement allows to convert these probe passages into emplacements for static pressure taps.

A remote traversing system capable of transmitting a rotatory or a translatory movement to the probe is mounted on the model base-plate in order to have an access to any desired measuring point in the fixed flow passages of the model. The traversing system support is made up of a rigid light alloy square tube, see Figure 5. The turntable, which allows the angular positioning, is mounted in one end of the tube. The turntable is supported 


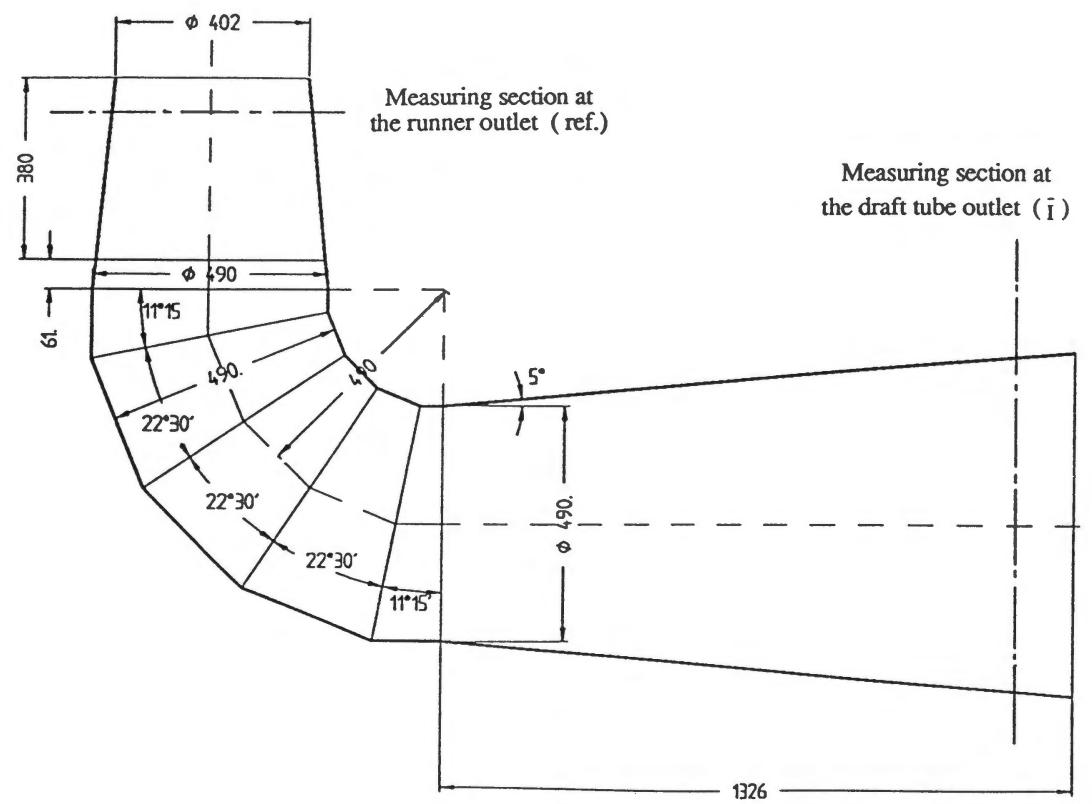

Fig. 3 Draft tube geometry

by a preloaded playless ball race and driven by a step motor with a worm and gear system. Linear motion is produced by using a step motor driven actuator mounted on the rotating part of the turntable and supported at the other end by a ball-bearing fitted into the square tube support of the traversing system. The linear drive system incorporates a fixed lead screw and a moving nut where the probe support is mounted.

Both the relative linear and angular positions are numerically read by optical shaft encoders mounted on the step motor shafts. To define an accurate origin for each axis of motion, electronic logic gates are used, firstly to rectify a contactless switch output and secondly to combine this output with the corresponding encoder signal output. The resulting signal is used to permit the resetting of the electronic counters. The sensitivity of one motor step corresponds to $6 \times 10^{-6} \mathrm{~m}$ and $10^{-2}{ }^{\circ}$ for the translational and the rotational motions, respectively. An accuracy of less than $\pm 20 \times 10^{-6} \mathrm{~m}$ and $\pm 0.2^{\circ}$ is achieved in the probe positioning. The linear positioning capacity is $0.3 \mathrm{~m}$ and the probe can be rotated through $360^{\circ}$.

\section{THE INSTRUMENTATION OF THE RUNNER}

The pressure transducers were mounted flush with the blade surfaces of the runner. The pressure transducers (resistive bridge) have been fitted on the model of the blades during the casting process. The wires of each full bridge were embedded in the carbon fiber and epoxy resin of the blades up to the hub of the runner. All the elements of processing and transmitting electronics were placed in the hub of the runner. The lead and signal wires were passed through the hollow shaft up to the transmitting coil. This assembling process allowed to place 3 transducers on each blade. In total 28 pressure transducers were installed on different blades, 17 of them were mounted on the suction side of the blades, and 11 on the pressure side, see Figure 6. 


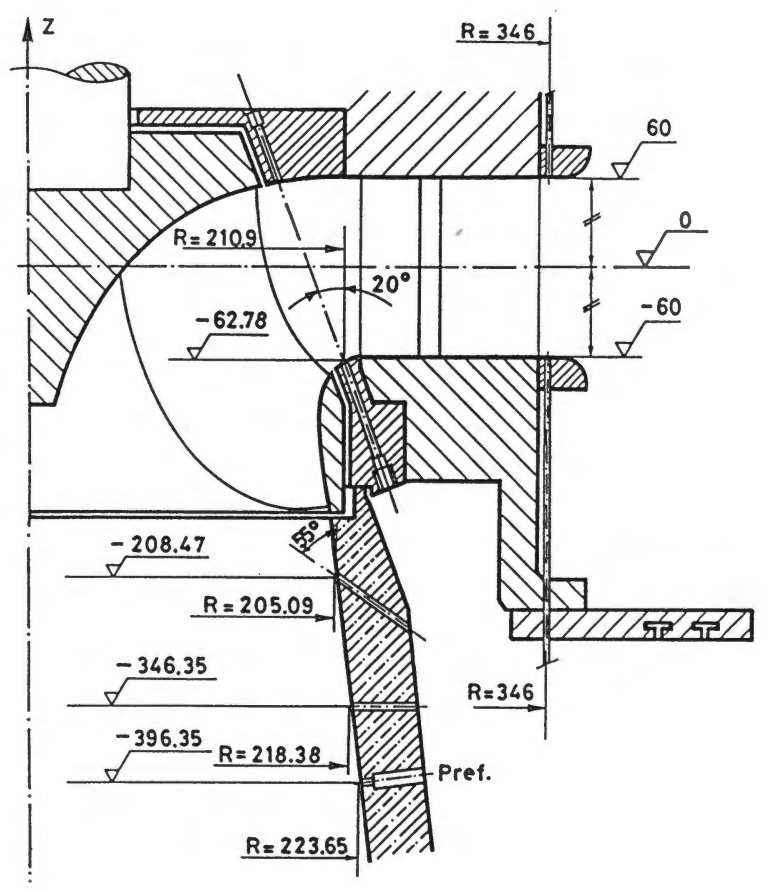

Fig. 4 Flow survey axes

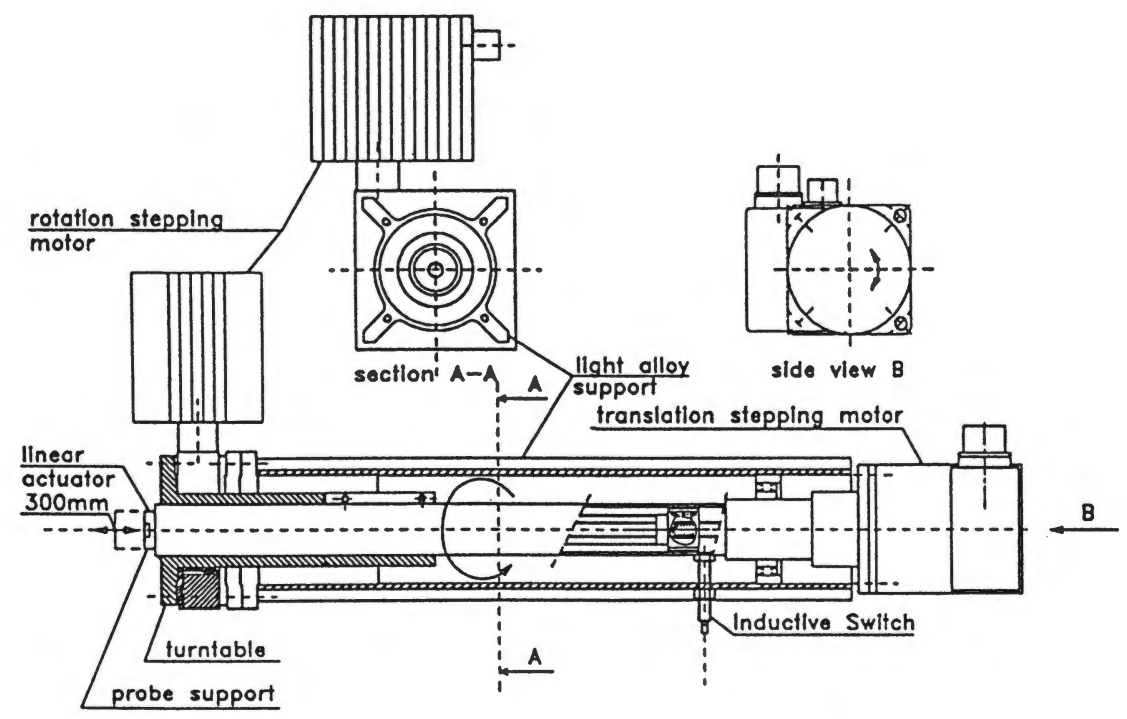

Fig. 5 Sketch of the traversing system 


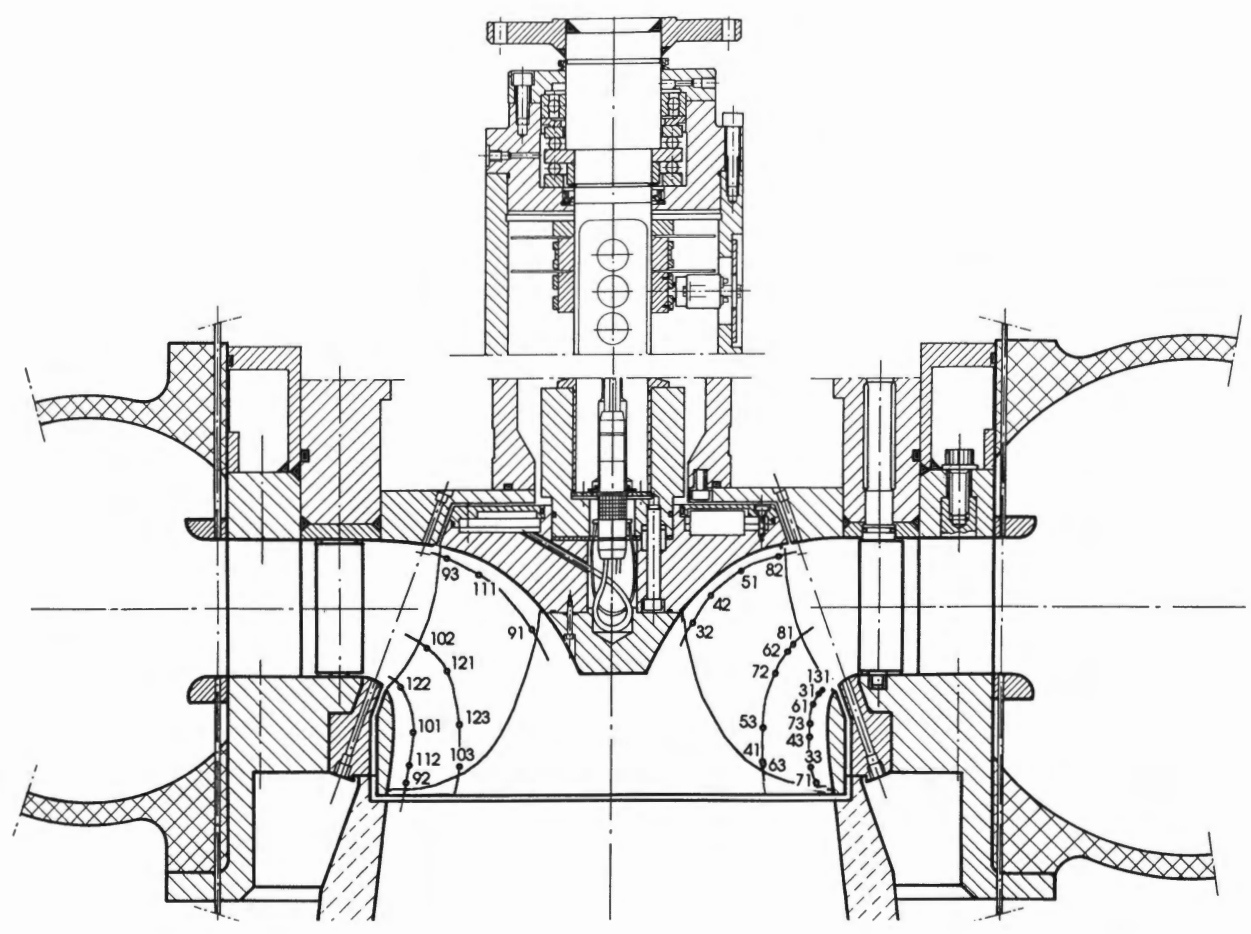

Fig. 6 Instrumented runner

PERFORMANCE TESTS

\section{HYDRAULIC CHARACTERISTICS}

Model tests were performed in the IMHEF Universal Hydraulic Machine Test Facility. Its principal characteristics are : a variable speed main pump of $900 \mathrm{~kW}$ at $1^{\prime} 000 \mathrm{rpm}$, capable of furnishing a maximum flow rate of $1.4 \mathrm{~m}^{3} / \mathrm{s}$, a test head range of $2-100 \mathrm{~m}$ with a maximum dynamometer power of $300 \mathrm{~kW}$ at a maximum speed of 2'500 rpm. The accuracy of the test instrumentations is far better than the IEC model turbine acceptance test code requirements.

The hydraulic characteristics for a given guide-vane opening angle are given in a normalized $\varphi-\psi$ form, see Figure 7. The model efficiency hillchart reported in the same figure presents two maxima caused by the poor pressure recovery of the conical draft tube.

\section{CONE REFERENCE}

The specific hydraulic energy was measured using two different downstream sections as shown in Figure 3 : 

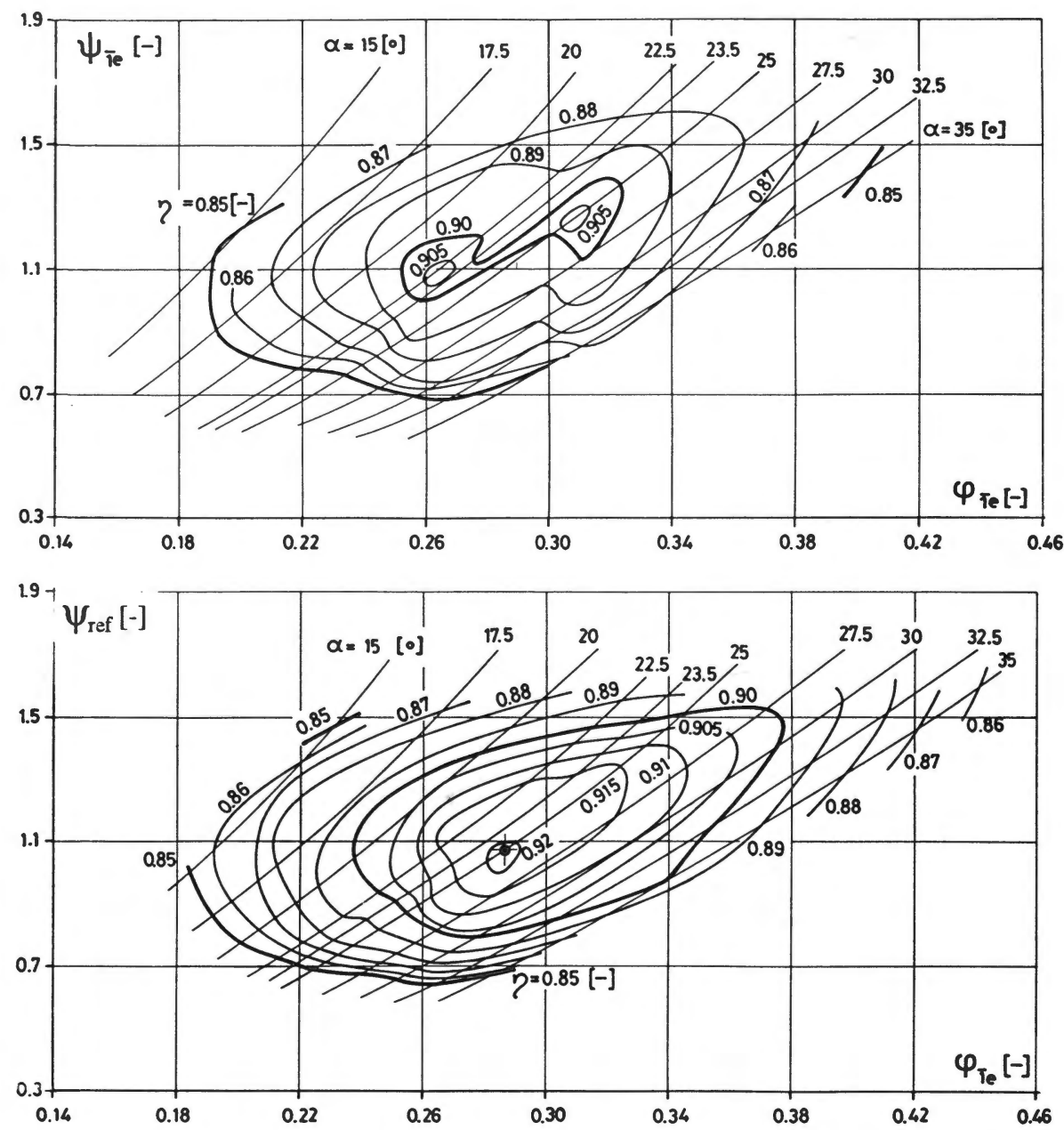

Fig. 7 Standard and cone reference model hillcharts

- the first (IEC defined) standard measuring section (I) is placed at the outlet of the draft-tube,

- the second (IMHEF defined) measuring section (ref) is close to the runner outlet.

The standard (IEC) specific hydraulic energy is given by

$$
E=\frac{p_{I}}{\rho}+\frac{Q_{I}^{2}}{2 S_{I}^{2}}+g Z_{I}-\frac{p_{\bar{I}}}{\rho}-\frac{Q_{\bar{I}}^{2}}{2 s_{\bar{I}}^{2}}-g Z_{\bar{I}}
$$

where the standard section (I) is taken at the machine inlet. 
The specific hydraulic energy using the runner outlet measuring section is given by

$$
E_{\text {ref }}=\frac{p_{I}}{\rho}+\frac{Q_{I}^{2}}{2 S_{I}^{2}}+g Z_{I}-\frac{p_{r e f}}{\rho}-\frac{Q_{\text {ref }}^{2}}{2 S_{\text {ref }}^{2}}-g Z_{\text {ref }} .
$$

The corresponding energy coefficients are defined as follows

$$
\begin{aligned}
& \psi_{\bar{T}_{\mathrm{e}}}=\frac{2 \mathrm{E}}{\omega^{2}\left(\mathrm{R}_{\overline{\mathrm{T}}_{\mathrm{e}}}\right)^{2}}, \\
& \Psi_{\mathrm{ref}}=\frac{2 \mathrm{E}_{\mathrm{ref}}}{\omega^{2}\left(\mathrm{R}_{\overline{\mathrm{Ie}}}\right)^{2}} .
\end{aligned}
$$

With these reference values, the problem of the poor draft-tube behaviour which gave an unusual hillchart with two peaks is solved. Thus, the modified energy coefficient $\psi$ ref and the efficiency were computed using this reference station, and are reported as a function of the discharge coefficient in the hillchart in Figure 7. In this case the best efficiency operating point leads to an efficiency $\eta=0.92$ for a discharge coefficient of $\varphi \mathrm{Ie}_{\wedge}=0.286$, and an energy coefficient of $\psi \mathrm{ref}=1.072$, with an opening angle of guidevanes $\alpha=25^{\circ}$, thereby, giving the value of $\gamma_{d}=30.37^{\circ}$, see Figure 1 , which is slightly different from what was enounced, $\gamma_{d}=28.25^{\circ}$.

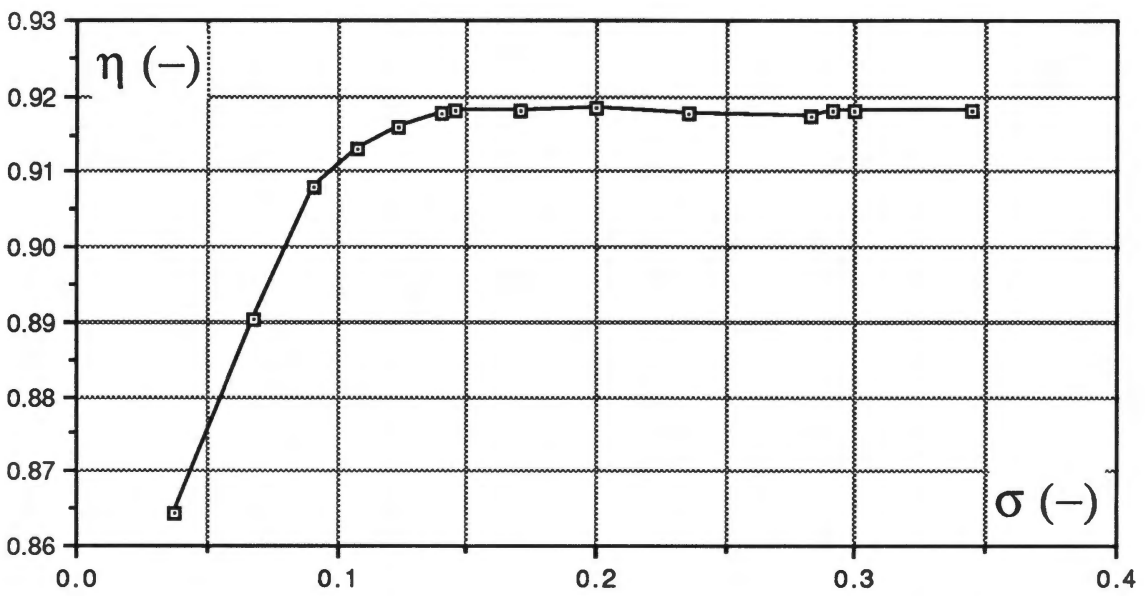

Fig. 8 Efficiency versus $\sigma$ for the best efficiency point 


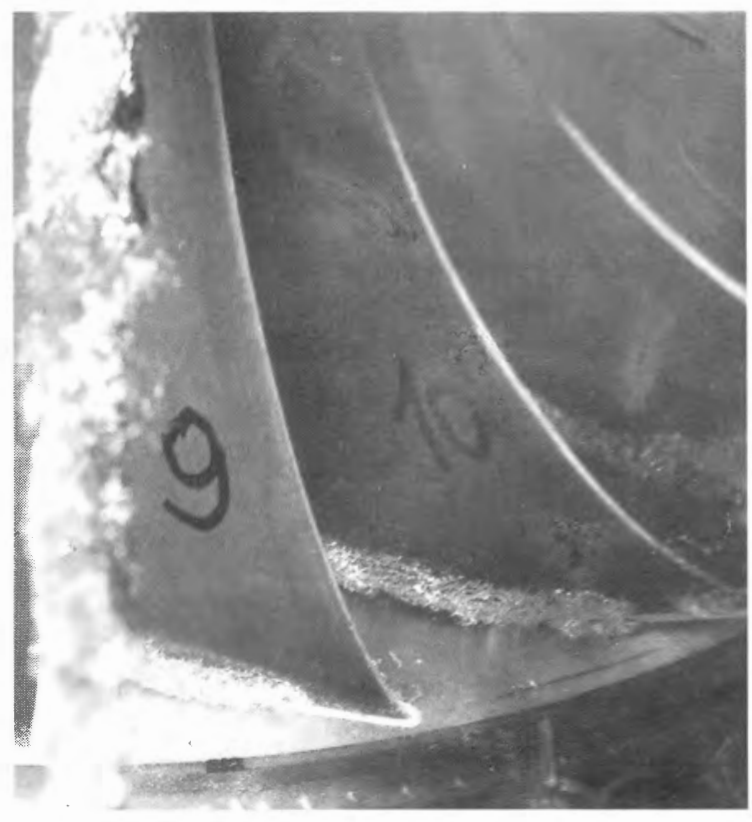

$$
\sigma=0.14
$$

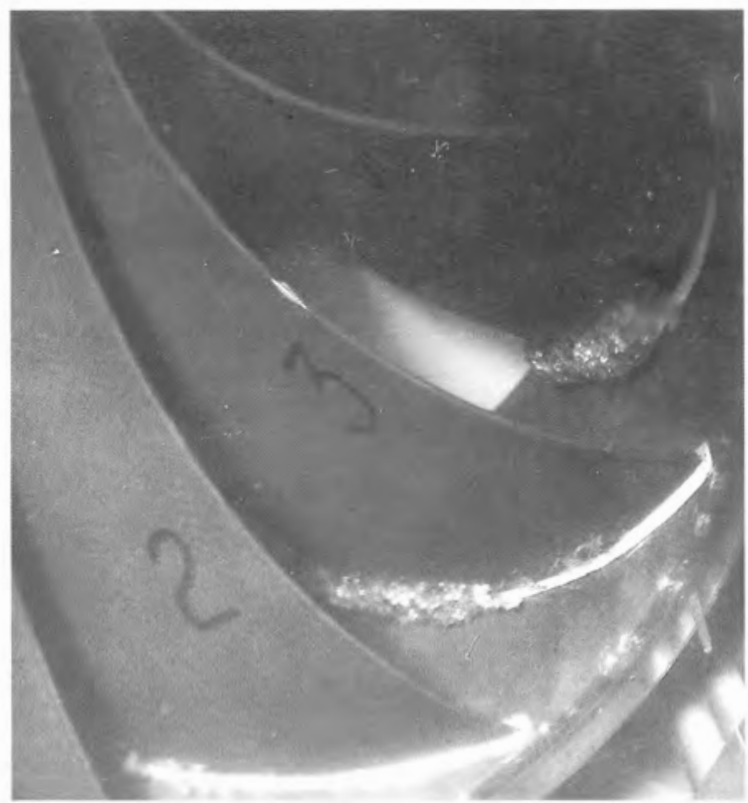

$\sigma=0.20$

Fig. 9 Photography of the inlet edge cavitation development at the best efficiency operating point 


\section{Cavitation}

The cavitation behaviour of the runner is also very interesting since it provides a rough idea of the pressure distribution in the runner. Figure 8 gives the efficiency versus $\sigma$ for the best efficiency operating point $\left(\varphi \mathrm{T} \mathrm{e}_{\Lambda}=0.286, \psi \mathrm{re} f=1.072\right)$.

The inlet edge cavitation at the suction side begins at $\sigma=0.30$. Photography represented on Figure 9 shows the extension of inlet edge cavitation for $\sigma=0.14$ and $\sigma=0.20$. This cavity development is important and shows that the pressure near the inlet edge, close to the band on the suction side is equal to the vapour pressure below $\sigma=0.30$.

\section{FLOW SURVEY INSTRUMENTATION}

\section{FIVE-HOLE PROBE}

\section{Design}

The $6 \mathrm{~mm}$ diameter five-hole probe was designed to perform a full traversing survey of the flow in the different stations of interest by giving the 3 components of the local flow velocity and the local static pressure. The arrangement of the $0.5 \mathrm{~mm}$ diameter pressure tap holes is the same as that of the United Sensor's probe, see Figure 10. In this case the probe is extended by a rod in order to guide it in the probe passages. The rod diameter is the same as that of the probe outer tube. The guide bearings in the probe passages eliminate mechanical vibrations as far as possible and allow the flow profile to be measured right across the flow channel for relevant head and flow values.
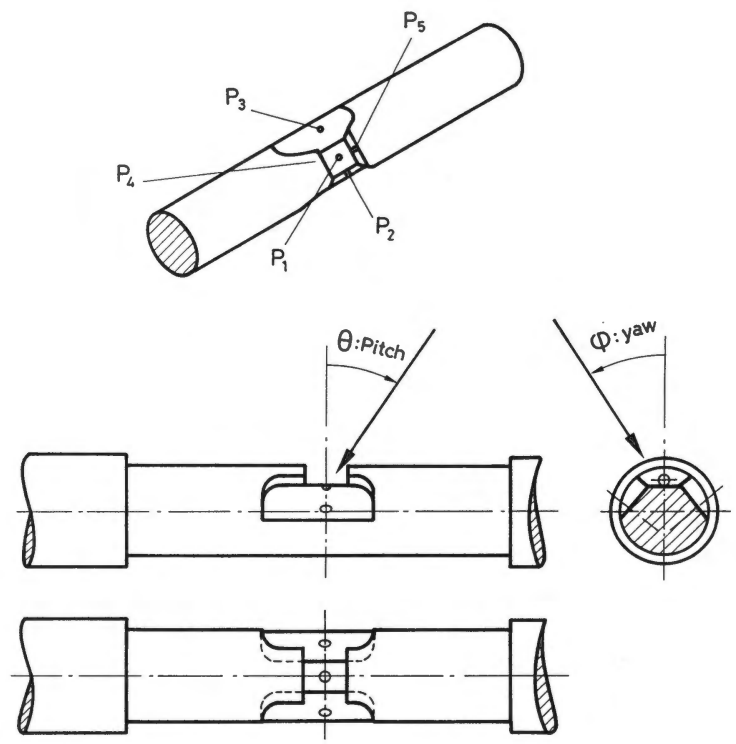

Fig. 10 Probe pressure tap arrangement 


\section{Static pressure measurements}

Static pressures are measured by a water pressure line scanning system. This system, driven by a micro-computer, uses two Scanivalves connected to an absolute pressure transducer. The transducer is isolated from the facility water by silicone oil and automatic draining is performed as long as necessary to remove all the unwanted bubbles maintained in every pressure line. In addition to the five pressure taps of the probe, the pressure taps of the reference model inlet station, the cone station and all the other sets of pressure taps in the model are connected to the scanning line system.

\section{Calibration}

The probe was calibrated in the test section of the IMHEF High-Speed Cavitation Tunnel. Absolute pressure measurements corresponding to the five holes were carried out for different pitch and yaw angles of the probe as a function of the flow velocity, the total pressure, pt, and the static pressure, po, in the test section. With the pressures p2, p3, p4 and p5, see Figure 10, one can define the average pressure $\mathrm{pm}$ as follows:

$$
\mathrm{pm}=(\mathrm{p} 2+\mathrm{p} 3+\mathrm{p} 4+\mathrm{p} 5) / 4 \text {. }
$$

With this definition, the following coefficients $F$ and $G$ were introduced as functions of the yaw angle $\Phi$ and the pitch angle $\theta$ :

$$
\mathrm{F}(\Phi, \theta)=\frac{\mathrm{p} 2-\mathrm{p} 3}{\mathrm{p} 1-\mathrm{pm}} \quad \text { and } \quad \mathrm{G}(\Phi, \theta)=\frac{\mathrm{p} 4-\mathrm{p} 5}{\mathrm{p} 1-\mathrm{pm}},
$$

where the difference $\mathrm{p}_{1}-\mathrm{pm}$ behaves like a dynamic pressure in the range of the yaw angles.

Calibration curves are given in Figure 11 as contoured surfaces of $F$ and $G$ values in a $\Phi$ versus $\theta$ graph. It can be observed that $F$ is almost independent of $\theta$ and the $G$ coefficient is independent of $\Phi$. In contrast to the $F$ coefficient the $G$ coefficient is not well-defined for the value of the yaw angle greater than $15^{\circ}$ or smaller than $-15^{\circ}$.
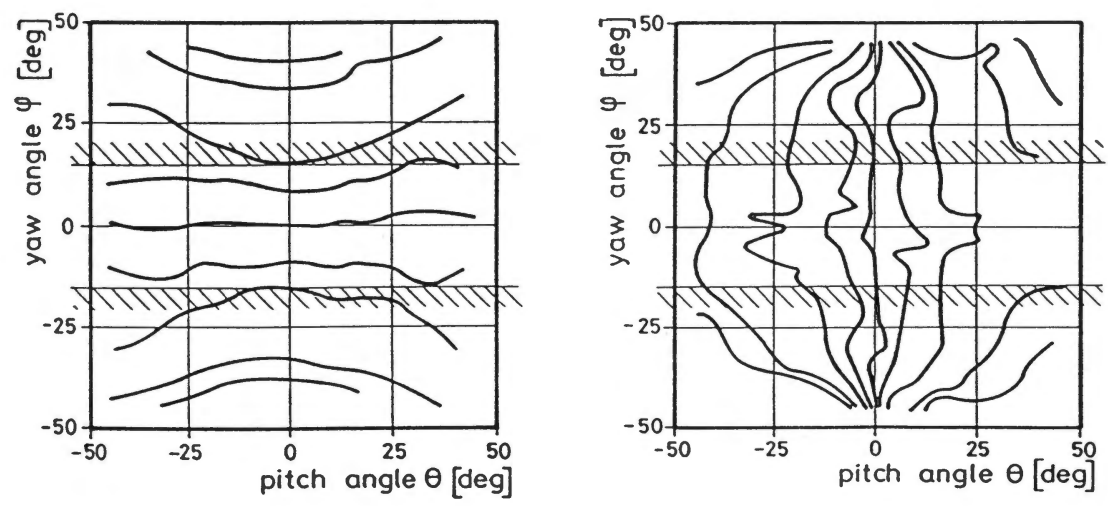

Fig. 11 Calibration surfaces of the yaw and pitch angles 
In addition, the coefficients $\mathrm{H}$ and $\mathrm{L}$ can be defined as functions of the static pressure po and the total pressure pt. The corresponding calibration curves are given in Figure 12 as contoured surfaces of $\mathrm{H}$ and $\mathrm{L}$ values in a $\Phi$ versus $\theta$ graph.

$$
\mathrm{H}(\Phi, \theta)=\frac{\mathrm{p} 1-\mathrm{pm}}{\mathrm{pt}-\mathrm{p} 0} \quad \text { and } \quad \mathrm{L}(\Phi, \theta)=\frac{\mathrm{p} 1-\mathrm{pt}}{\mathrm{pt}-\mathrm{p} 0}
$$
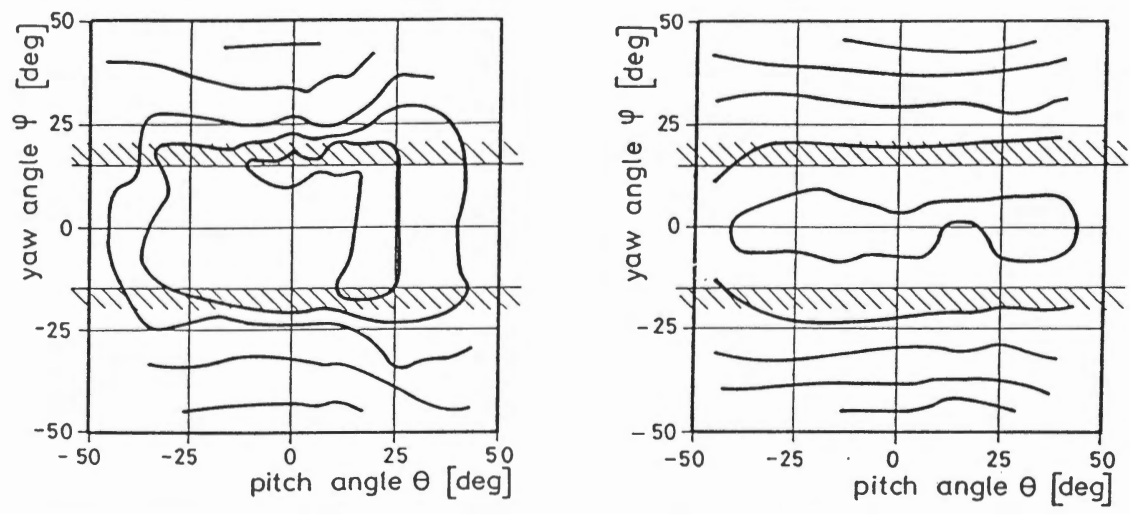

Fig. 12 Calibration surfaces of the total and static pressure

It is to be noted that, these strongly contoured curves represented in Figures. 11 and 12 are repetetive and the interpolated values are to be really read on the curves by successive approximation.

During the flow survey, the corresponding pressure values allow us to compute the $\mathrm{F}$ and $\mathrm{G}$ coefficients in order to find a corresponding pair of $\Phi, \theta$ angles. The $\mathrm{H}$ and $\mathrm{L}$ coefficients are then calculated with the help of angle values, which, in turn lead to the static and the total pressure. The local velocity $\mathrm{C}$ is then computed according to the definition of the dynamic pressure :

$$
C=\sqrt{\frac{p t-p 0}{\frac{1}{2} \rho}} .
$$

\section{FLOW MEASUREMENT}

The calibrated probe is mounted at the end of the linear actuator of the traversing system. The displacement origins are set using the switch references. The five probe pressures and those at the inlet reference and at the cone reference stations are measured sequentially. The flow angles are determined, and if the the yaw angle $\Phi$ is not within a range of $\pm 15^{\circ}$, the probe is rotated into the specified range to achieve good accuracy for the flow velocity. The flow angle, the velocity intensity and static pressure are computed in the model frame of reference according to the definition in Figure 13.

Even though the actual flow rate value cannot be sampled simultaneously with the probe pressure measurement, this pressure scaling, related to the reference pressure using a value similar to a kinetic energy term, allows a comparison of the measurements, taken for different test heads. These coefficients are then related to the reference specific energy provided by the test-rig measuring system. 


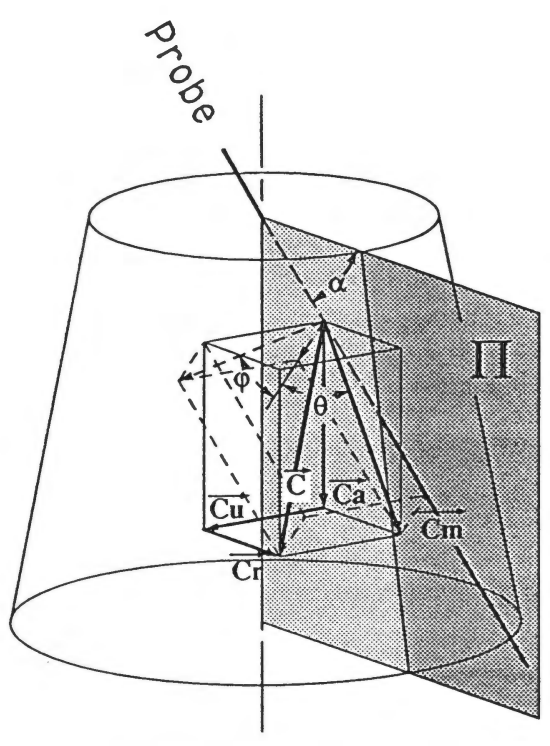

$$
\begin{aligned}
{\left[\begin{array}{l}
\mathrm{C}_{\mathrm{r}} \\
\mathrm{C}_{\theta} \\
\mathrm{C}_{z}
\end{array}\right] } & =\left[\begin{array}{l}
\mathrm{C}_{\mathrm{r}} \\
\mathrm{Cu}_{\mathrm{u}} \\
-\mathrm{C}_{2}
\end{array}\right] \\
& =\mathrm{C} \cdot\left[\begin{array}{ccc}
-\sin \alpha & 0 & \cos \alpha \\
0 & 1 & 0 \\
-\cos \alpha & 0 & -\sin \alpha
\end{array}\right] \cdot\left[\begin{array}{c}
\cos \theta \cos \Phi \\
\cos \theta \sin \Phi \\
\sin \theta
\end{array}\right]
\end{aligned}
$$

Fig. 13 Velocity component in the probe frame of reference. In this case $\alpha$ is the angle of the probe axis with the radial direction in the meridional plan

To overcome any drift conditions in the test facility operations during the flow survey, the actual static and total pressures are scaled by using a kinetic energy term defined as follows :

$$
\mathrm{Ek}_{k}=\frac{\mathrm{pI}}{\rho}+\mathrm{gZI}-\frac{\text { pref }}{\rho}-\mathrm{gZref}
$$

in order to compute the static pressure and total pressure coefficients, Cpo(probe) and $\mathrm{Cpt}($ probe) are defined as :

$$
\mathrm{Cpo(probe)}=\frac{\mathrm{p} 0-\text { pref }}{\rho E k} \text { and } C p t(\text { probe })=\frac{p t-\text { pref }}{\rho E k} .
$$

Then the actual coefficient values are deduced by using the corresponding pair of kinetic energy term $\mathrm{Ek}$ and the specific energy $\mathrm{E}$ provided by the test rig panel control. Hence the coefficients are

$$
\mathrm{Cp}_{\mathrm{o}}=\mathrm{Cpo( \text {probe } )} \frac{E_{k}}{\mathrm{E}} \text { and } \mathrm{Cpt}=\mathrm{Cpt}\left(\text { probe) } \frac{E k}{E} .\right.
$$

This leads to the following definition of the velocity coefficient $\mathrm{c}$ :

$$
c=\frac{C}{\sqrt{2 E}} .
$$




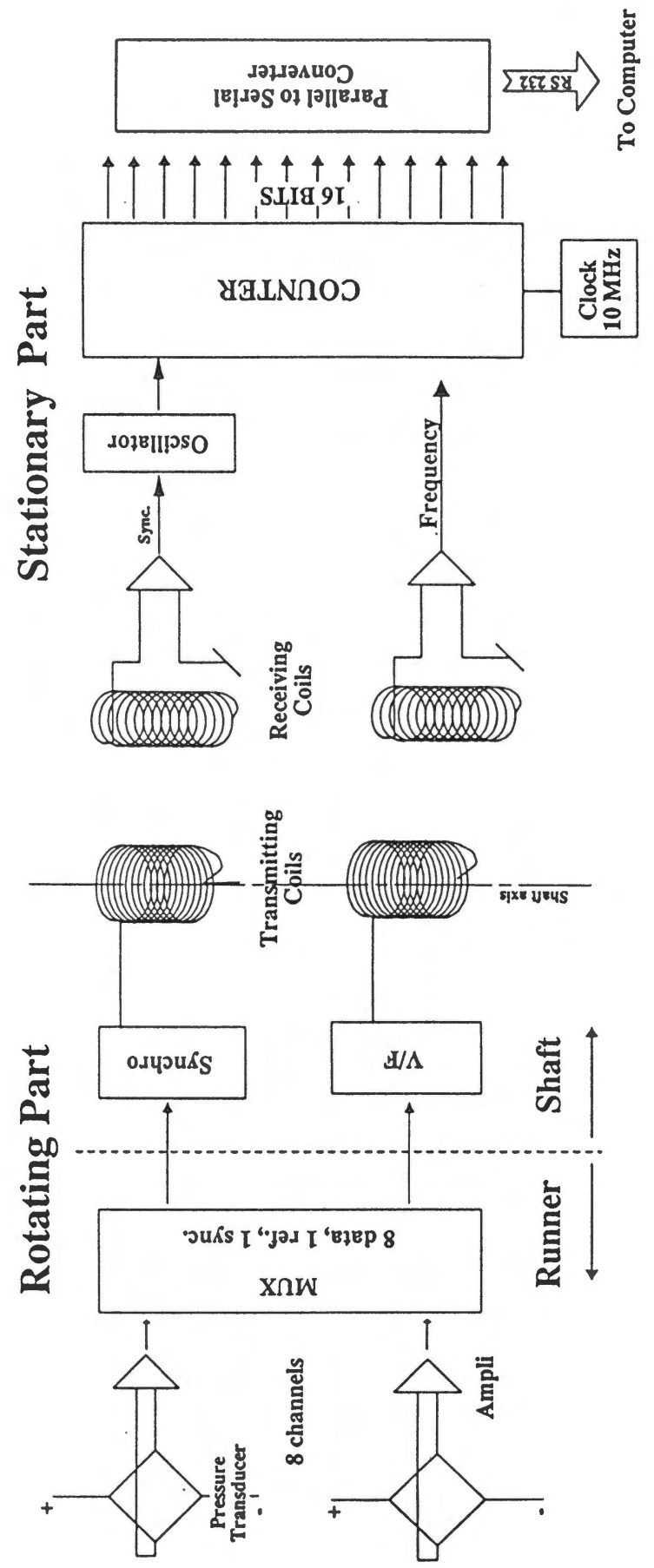

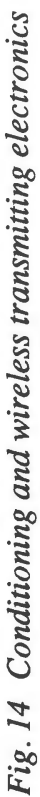




\section{PRESSURE MEASUREMENTS IN THE RUNNER}

The miniature absolute pressure transducers embedded in the runner blades are a Kyowa's resistive bridge-type PS-2KA model. Their diameter and thickness are $5 \mathrm{~mm}$ and $0.6 \mathrm{~mm}$, respectively. The pressure range is $2 \times 10^{5} \mathrm{~Pa}$ and the mean sensitivity $900 \mu \mathrm{V} / \mathrm{V}$. It should be noticed that the pressure should be always higher than the atmospheric pressure in order to avoid the destruction of transducers.

The multiplexed bridge signal is voltage to frequency converted in order to be transmitted through a coil mounted on the rotating shaft. The stationary part of the electronics consists of a receiving coil and a numerical counter driven through a serial interface by the microcomputer, Figure 14.

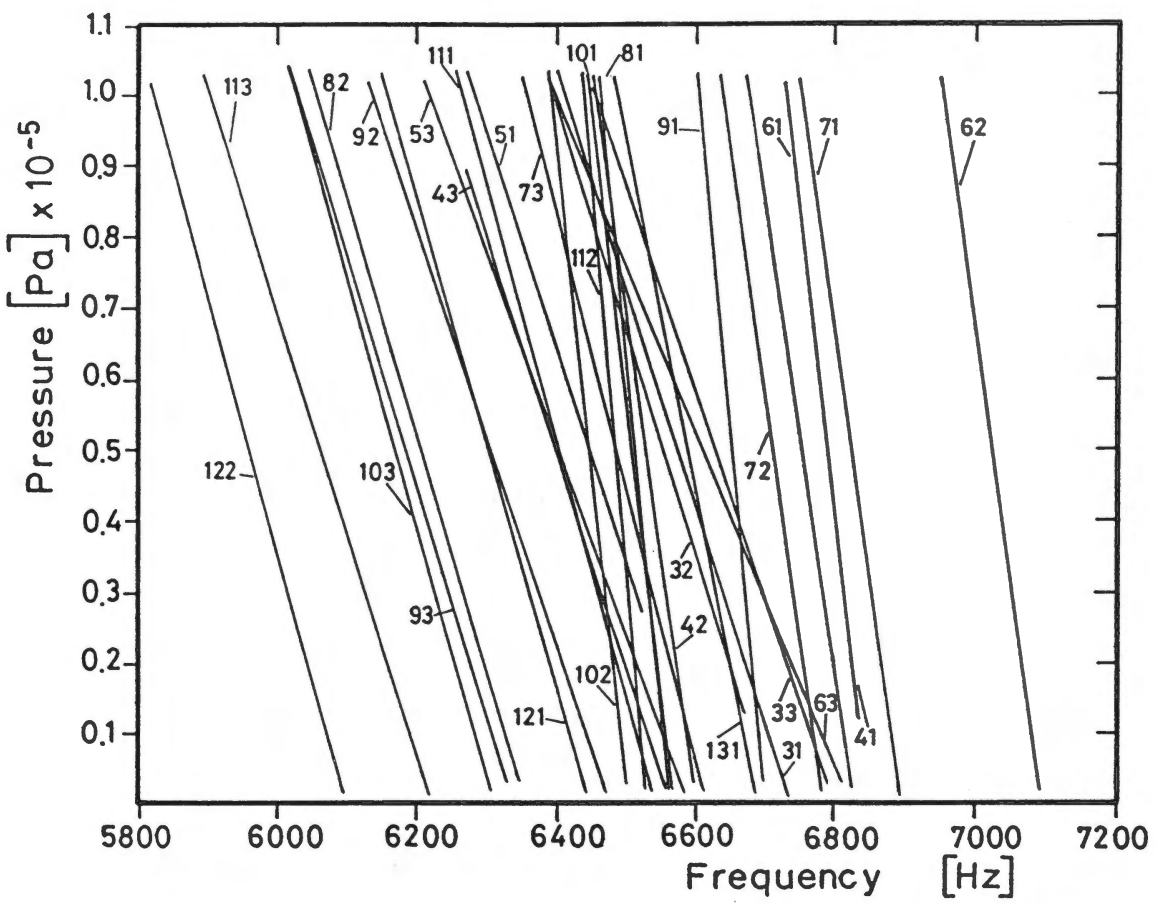

Fig. 15 Calibration curves of the rotating pressure transducers (see Figure. 6 for transducer identification)

When the runner is at rest, the pressure transducer is calibrated by varying the static pressure of the test-rig, Figure 15. The pressure distribution is obtained for a given operating point by scanning the 28 pressure transducers. The data is reduced by computing the time average of the pressure signal corresponding to the nth transducer and scaled as follows :

$$
C_{p}^{*}=\frac{p n-p r e f}{p I-p r e f}
$$



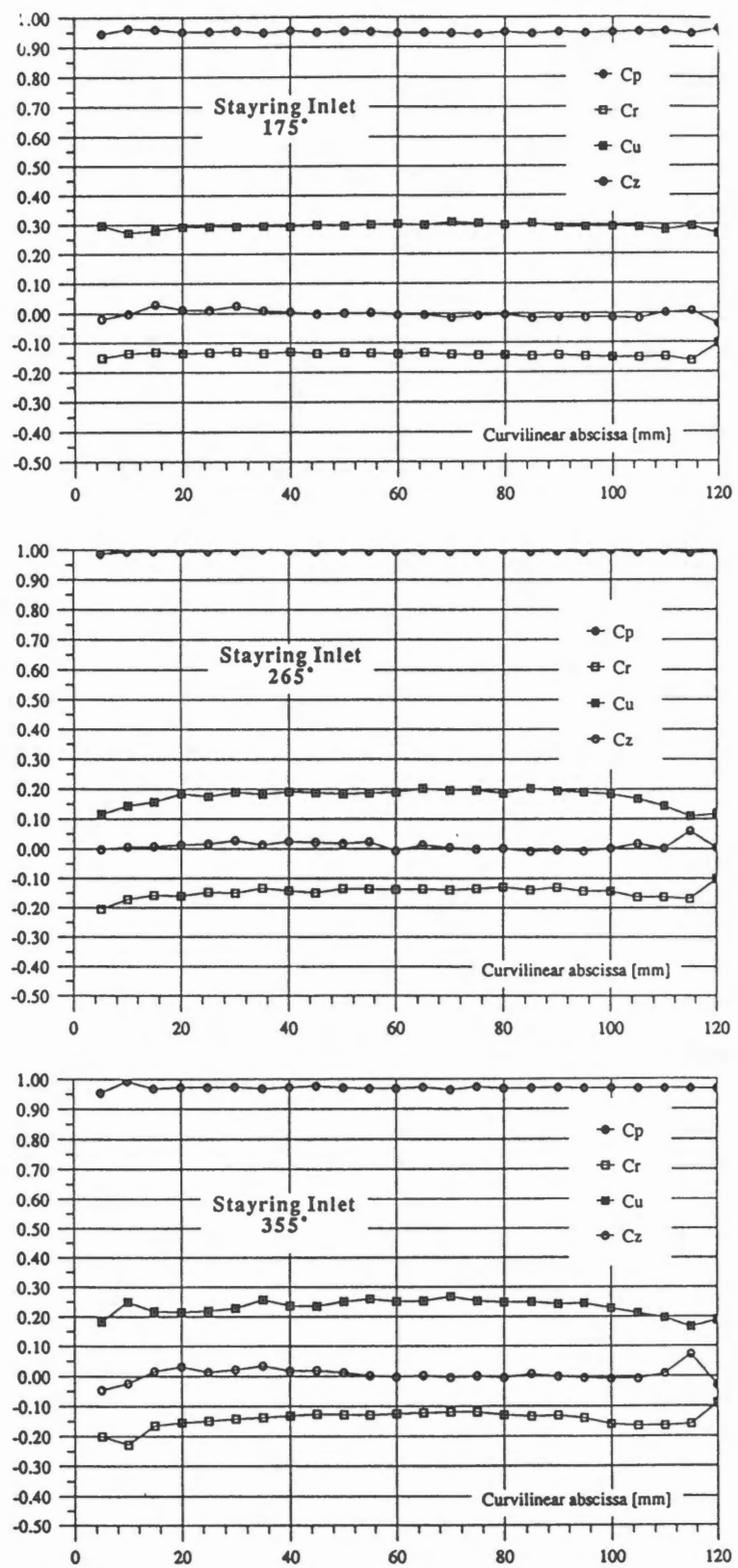

Fig. 16 Flow survey at the stayring inlet 
These values are then related to the specific energy $E$ provided by the test-rig measuring system in order to define the following pressure coefficient $C_{p}$ of the nth transducer :

$$
\mathrm{C}_{\mathrm{p}}=\mathrm{C}_{\mathrm{p}}^{*} \frac{\mathrm{pI}-\mathrm{pref}}{\rho \mathrm{E}}
$$

\section{RESULTS}

\section{FLOW SURVEY}

The operating point investigated in this study corresponds to the best efficiency point of the hillchart in Figure 7 : the flow coefficient $\varphi \overline{1} e_{\wedge}$ and the energy coefficient $\psi$ ref are 0.286 and 1.072 , respectively, and the guide-vane opening angle $\alpha$ is $25^{\circ}$.

\section{Stayring inlet}

Data corresponding to the flow survey at the stayring inlet is given in Figure 16. Static and total pressure coefficients $\mathrm{C}_{\mathrm{p}}$ and $\mathrm{Cpt}_{\mathrm{pt}}$ and coefficients corresponding to the three flow velocity components are provided versus the traversing axis coordinates. Three sets of curves are given for a $\theta$ value of $175^{\circ}, 265^{\circ}$ and $355^{\circ}$, respectively. Owing to the influence of the fillet the flow is quasi two-dimensional, the $\mathrm{cz}_{\mathrm{z}}$ component being zero and the radial component remaining constant all along the periphery. A tangential component of the velocity coefficient $\mathrm{cu}$ appears at these stations due to flow deviation by the stay vanes. Thus, the corresponding flow angle is very close to the stay vane angle $\left(\gamma_{\mathrm{ad}}=34^{\circ}\right)$.

\section{Runner inlet}

At the runner inlet no significant difference can be detected between the data obtained at different probe passages of this station. The mean flow is seen as axisymmetric by the pressure probe, thus the data reported in Figure 17 corresponds to the overall average of the measurements carried out at each probe passage. The tangential velocity component $\mathrm{cu}$, is uniform across the channel at the runner inlet. According to the channel geometry the meridional flow is deviated towards the vertical axis with an acceleration in the shroud region.

\section{Cone section}

The flow survey at the runner outlet shows a uniform meridional flow except in the mid core region, where the wake of the hub is felt $(\mathrm{R}<40 \mathrm{~mm})$, Figure 18 . The positive value of the radial velocity component close to the wall of the cone ( $R>180 \mathrm{~mm}$ ) corresponds to the cone divergence. The linear outer distribution of the tangential component $\mathrm{cu}$ is imposed by the trailing edge blade angle. Meanwhile a positive solid body rotation starts at the cone axis, extending up to $R=20 \mathrm{~mm}$. The static pressure distribution is uniform except in the axis region where a lower pressure leads to predicting the onset of a whirl (see Figure 9).

\section{Draft tube outlet}

A set of probe passages were made at the draft tube outlet in order to perform a flow survey with a five hole probe. Unfortunately the large random flow instabilities did not allow to carry out precise velocity measurements with the probe. Nevertheless, wall pressure measurements were made at this section. 


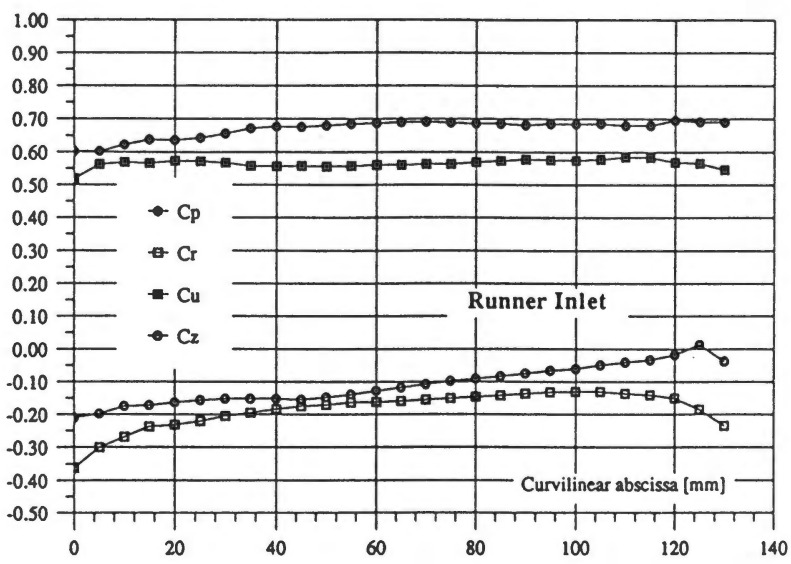

Fig. 17 Flow survey at the runner inlet

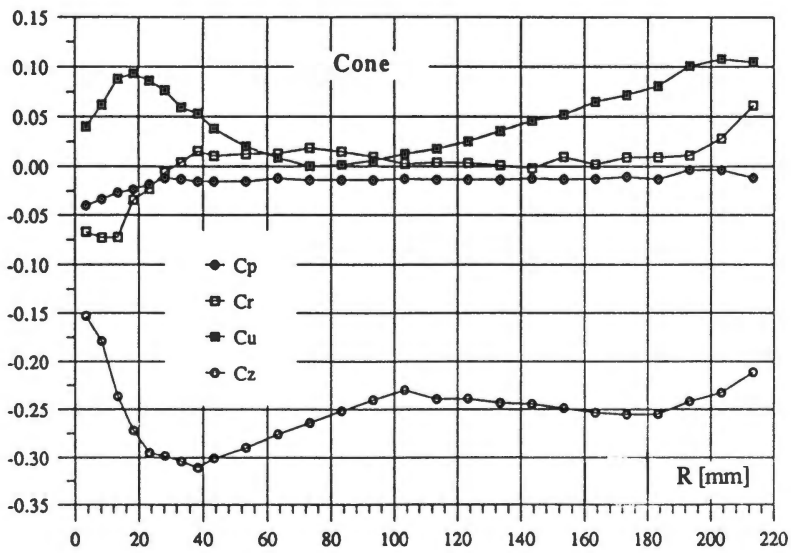

Fig. 18 Flow survey at the cone section

\section{PRESSURE DISTRIBUTION IN THE RUNNER}

The distribution of pressure coefficient along three theoretical streamlines close to, hub, shroud, and that corresponding to a midspan position is given in Figure 19, which represents only the second series of measurements in order to have a better readability. These values show that even at the best efficiency point the blade loading is far from optimal. There is low pressure distribution close to the shroud, leading to an inlet cavity development at the leading edge. Moreover, the strong adverse pressure gradient could lead to a possible flow separation.

The test was performed at a very high $\sigma$ value $(\sigma \approx 1.5)$, in order to have a pressure, higher than the atmospheric pressure, on the transducers. The specific hydraulic energy for this test was $\mathrm{E} \approx 58\left[\mathrm{~J} \cdot \mathrm{kg}^{-1}\right]$. 


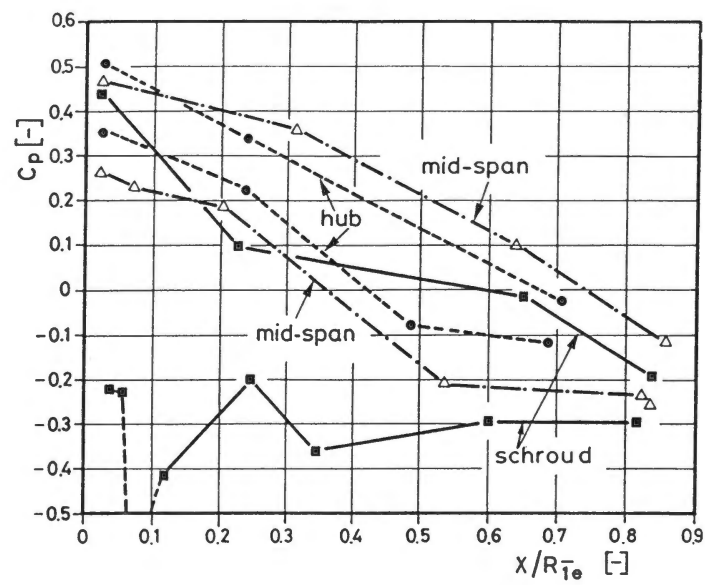

Fig. 19 Blade pressure

\section{CONCLUSIONS}

A complete experimental set-up has been developed in order to perform a flow study in a model of a Francis turbine. A five-hole probe mounted on a remote traversing system provides static pressure and velocity components along three stations in the machine. An original instrumentation is installed in the rotating runner in order to obtain the pressure distribution on the blades along three theoretical streamlines. This flow survey in the model provides an experimental set of data for CFD codes in order to check their ability to represent the flow in the complex geometry of a Francis turbine. Even though the accuracy of local velocity measurements can be improved, the experimental procedure provides an understanding of the flow conditions of hydraulic machines .

\section{ACKNOWLEDGEMENT}

The authors thanks all their colleagues and the technical staff of the IMHEF Test Rig.

\section{REFERENCE}

[1] HENRY, P. : "Hydraulic machine model acceptance tests", Proceedings of International Conference on Hydropower, Water Power '85, Las Vegas, 1985, vol. 2, pp. 1258-1267. 


\section{NOTATIONS}

\begin{tabular}{|c|c|c|c|c|}
\hline $\mathrm{C}$ & $:$ & Absolute velocity & & {$\left[\mathrm{m} \cdot \mathrm{s}^{-1}\right]$} \\
\hline $\mathrm{Cr}$ & : & $\begin{array}{l}\text { Radial component of the absolute } \\
\text { velocity }\end{array}$ & & {$\left[\mathrm{m} \cdot \mathrm{s}^{-1}\right]$} \\
\hline $\mathrm{Cz}=-\mathrm{Ca}$ & : & $\begin{array}{l}\text { Axial component of the absolute } \\
\text { velocity }\end{array}$ & & {$\left[\mathrm{m} \cdot \mathrm{s}^{-1}\right]$} \\
\hline $\mathrm{Cu}=\mathrm{C} \theta$ & : & $\begin{array}{l}\text { Peripheral component of the } \\
\text { absolute velocity }\end{array}$ & & {$\left[\mathrm{m} \cdot \mathrm{s}^{-1}\right]$} \\
\hline $\mathrm{E}$ & : & Specific hydraulic energy & & {$\left[\mathrm{J} \cdot \mathrm{kg}^{-1}\right]$} \\
\hline Ek & : & Specific kinetic energy & & {$\left[\mathrm{J} \cdot \mathrm{kg}^{-1}\right]$} \\
\hline $\mathrm{E}_{\text {ref }}$ & : & Specific hydraulic energy & & {$\left[\mathrm{J} \cdot \mathrm{kg}^{-1}\right]$} \\
\hline $\mathrm{F}$ & : & Calibration coefficient & & {$[-]$} \\
\hline G & : & Calibration coefficient & & {$[-]$} \\
\hline $\mathrm{H}$ & : & Calibration coefficient & & {$[-]$} \\
\hline $\mathrm{H}_{\mathrm{s}}$ & : & Suction Head & Zref - Zì & [m] \\
\hline I & : & $\begin{array}{l}\text { Measuring section at the inlet of } \\
\text { the spiral casing }\end{array}$ & & {$[-]$} \\
\hline$\overline{\mathrm{I}}$ & : & $\begin{array}{l}\text { Measuring section at the outlet of } \\
\text { the draft tube }\end{array}$ & & {$[-]$} \\
\hline $\mathrm{L}$ & : & Calibration coefficient & & {$[-]$} \\
\hline Q & : & Flow rate & & {$\left[\mathrm{m}^{3} \cdot \mathrm{s}^{-1}\right]$} \\
\hline $\mathrm{R}$ & : & Radius & & [m] \\
\hline $\mathrm{R}_{\mathrm{ie}}$ & : & Reference radius at runner outlet & & [m] \\
\hline$S$ & : & Surface & & {$\left[\mathrm{m}^{2}\right]$} \\
\hline $\mathrm{Z}$ & : & Altitude & & {$[\mathrm{m}]$} \\
\hline c & : & Velocity coefficient & & {$[-]$} \\
\hline $\mathrm{g}$ & : & Acceleration due to gravity & & {$\left[\mathrm{m} \cdot \mathrm{s}^{-2}\right]$} \\
\hline $\mathrm{nq}$ & : & Specific speed & & {$[-]$} \\
\hline $\mathrm{p}$ & : & Static pressure & & {$[\mathrm{Pa}]$} \\
\hline $\mathrm{pa}$ & : & Atmospheric pressure & & {$[\mathrm{Pa}]$} \\
\hline $\mathrm{pm}$ & : & Average pressure & & {$[-]$} \\
\hline pt & : & Total pressure & & {$[\mathrm{Pa}]$} \\
\hline $\mathrm{p}_{\mathbf{v}}$ & : & Vapour pressure & & {$[\mathrm{Pa}]$} \\
\hline
\end{tabular}


$\alpha \quad$ : Guide vane opening

$\Phi \quad$ : Yaw angle

$\gamma_{\text {do }}:$ Guide vane closed position angle

$\eta \quad$ : $\quad$ Model turbine efficiency

$\varphi \mathrm{I} \mathrm{e}_{\wedge} \quad$ : Discharge coefficient

$$
\begin{aligned}
& \frac{\mathrm{Q}}{\pi \omega\left(\mathrm{R}_{\mathrm{i}}\right)^{3}} \\
& \frac{\omega(\mathrm{Q} / \pi)^{1 / 2}}{(2 \mathrm{E})^{3 / 4}}
\end{aligned}
$$

$\theta \quad$ : Pitch angle

$\theta_{\mathrm{d}} \quad: \quad$ Guide vane angular position

$\theta_{\mathrm{ad}} \quad: \quad$ Stay vane angular position

$\rho \quad$ : Water density

$\sigma \quad: \quad$ Thoma's cavitation number

$\frac{p_{a}-p_{v}-\rho g H_{S}}{\rho E}$

$\omega \quad$ : Angular speed

$\left[\mathrm{rad} \cdot \mathrm{s}^{-1}\right]$

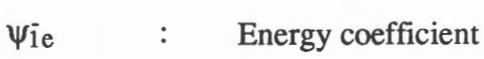

$\frac{2 \mathrm{E}}{\omega^{2}\left(\mathrm{R}_{1 \mathrm{e}}\right)^{2}}$

[-]

$\psi_{\text {ref }} \quad: \quad$ Energy coefficient

$\frac{2 E_{\text {ref }}}{\omega^{2}\left(R_{1 \mathrm{e}}\right)^{2}}$ 
